\title{
The Importance of the Doctor-Patient Relationship in Adherence to HIV/AIDS Treatment: A Case Report
}

\author{
Rosa Garcia, Manuela Garcia Lima \\ Miriam Gorender and Roberto Badaró
}

\author{
Federal University of Bahia, Salvador, BA, Brazil
}

\begin{abstract}
In this case report, which includes a statement related by the patient himself, the authors also discuss the importance of a good doctor-patient relationship in treating HIV patients and in assuring the patient's adherence to his treatment. Related issues, such as the importance of treating psychiatric comorbidities, of preserving the patient's hope and motivation, and of giving him an adequate amount of information regarding the disease and its treatment, are also discussed. Key Words: Adherence, doctor-patient relationship, HIV, AIDS, psychiatric comorbidities.
\end{abstract}

Adherence has been called the Achilles' heel of highly active antiretroviral therapy (HAART), and is a major issue in HIV treatment. It refers to how closely one follows a prescribed treatment management. Adherence helps decrease viral load, also preventing drug resistance, which is essential in preventing AIDSrelated conditions and death. Since the appearance of ARV treatment, a significant improvement has been seen in patients' quality of life [1,2]. AIDS thus became a chronic disease; however, despite the enormous benefits originating from this therapy, several other nonmedical issues remain to be resolved, one of the most important being adherence to treatment [3].

Overall adherence is directly related to the degree of complexity of the course of treatment: the number of pills, frequency of administration, side effects, and whether or not the schedule of drug administration entails changes in dietary habits or lifestyle. To insure adherence, a trilogy composed of information, motivation and behavioral skills is essential in HAART [4].

Received on 15 January 2005; revised 18 May 2005.

Address for correspondence: Dr. Rosa Garcia. Avenida Sete de Setembro, 2141, apt. 902, Vitória. Zip code: 40080-002. Salvador/ BA, Brazil.

The Brazilian Journal of Infectious Diseases 2005;9(3):251-256 (C) 2005 by The Brazilian Journal of Infectious Diseases and Contexto Publishing. All rights reserved.

\section{Information}

Patients need to know about their medication, and information sources such as pamphlets and other printed material or videos can help them acquire this information. However, basic information may not be enough. Despite full comprehension of their disease and its potential consequences, some patients still may not comply with their medication regimens because of personal, cultural or other factors.

\section{Motivation}

When the patient is depressed, he/she does not want to be treated. Depression is strongly connected to motivation because depressed patients often fail to participate actively in their own care, and adopt negative attitudes [5]. In addition, patients define their own values, and if they have been consistently treated with consideration throughout their lives, they will be more motivated to adhere to treatment.

\section{Behavioral Skills}

Treatment must be adapted to the lifestyle of the individual patient; therefore his daily routine, which includes pill-taking, dietary patterns, job activities and 
biorhythms, must be monitored by his/her careproviders [6].

We relate a case report here, as told by the patient himself, which we believe clearly portrays the importance of the doctor-patient relationship in adherence of the patient to his treatment and in achieving a satisfactory outcome.

\section{Case Report}

G.R., 32 years old, single, owns a small business and lives in Salvador, Bahia, Brazil.

\section{$\underline{\text { Pateint's Report }}$}

The first time I ever heard of AIDS was at the end of the eighties. The mass media was referring to it as the "gay plague" or even as the "gay cancer", in a clear reference to the first people who became infected. A more conservative sector of the press referred to the illness as "God's Punishment", in a punitive reference to the sexual orientation of those infected with the disease.

I remember the first well-known victim of AIDS in Brazil, the fashion-designer, Markito. He was the first "celebrity" to die of AIDS. His death was broadcast nationwide, and between the lines one could read the critical inference that it was his lifestyle, sexual orientation and promiscuity that led to the disease. I am grateful for the opportunity to give this personal report that proves how prejudiced opinions can lead to a very narrow and erroneous view of facts.

In August 1995, I noticed a lump in my neck, and at first I simply didn't worry about it. However, it kept growing and I decided to see a doctor. I did not inform him of my bisexuality as I considered it a private matter that bore no relevance to the situation in question. He thought it might be a lymphoma and asked for a biopsy. The result was negative for Hodgkin's lymphoma and suggestive of ganglionic tuberculosis. I decided to consult a specialist. By this time, I was forced to confront the very strong possibility of AIDS, which was unfortunately confirmed through various blood tests, including a positive Elisa serologic test. In November 1995, I learned that I had definitely been infected with the AIDS virus.

My doctor, who worked for the public health system, referred me to a female doctor in a private clinic, whose fees were covered by my private health insurance. The consultation with this physician turned to be one of the most negative emotional experiences I've ever been through.

My parents decided to go with me to this consultation. They have always supported me, both emotional and financially, and I firmly believe that this support has been the main pillar in my daily fight for survival.

We were hoping for an optimistic management of the treatment that I would have to undergo, but we were far from finding it on that occasion. My father told the doctor the reason for our consultation, she listened to him and then asked them to leave the office and wait outside. When we were alone, she asked me how I felt with respect to the fact that I was dying. She put me down, and I felt as if I was going to faint. My whole being suffered and I bore very strong feelings of anger against her as a doctor, but I could not find a single word either to answer her question or to tell her of the indignation I felt towards her.

I lacked the strength to argue with her. I felt lost, but since the previous doctor had recommended her so highly, I did not immediately make the decision to change physicians. However, after another five weeks I left her care because of a series of facts of which I would like to describe just two. First, she refused to put me on retroviral therapy, which was my only hope for survival. Second, at the end of December I had a very high fever for three days in a row, so I called her on the phone and she told me I had to get used to it; that from now on this was the way it was going to be, right up to the end. That was enough. I was sure I did not deserve to be treated this way.

I chose a new doctor I had never heard of. To tell you the truth, I chose him because I liked the sound of his name. This time, however, I was lucky, for he has proved to be highly qualified both to deal with the 
disease and to deal with the human emotions and fragility that are a result of the illness.

When I first met this doctor, I had lost all hope. I believed I was dying, and the only thing I was looking for was dignity and help in the last moments of my life. I had no hopes of getting any better or even of surviving. That was January 1996, the date of my rebirth. My $\mathrm{CD}_{4}$ count was above 200 cells $/ \mathrm{mm}^{3}$ and from that day on my health began to improve considerably. I am now absolutely sure that the second pillar of support for any successful treatment is a high level of interaction between the patient and a competent doctor.

Between August 1995 and January 1996, I lost 20 $\mathrm{Kg}$. I started taking AZT and 3TC, plus a triple combination of anti-tuberculosis drugs, among them rifampicin. I had a very good, rapid response to the treatment. One month later, the ganglions, which had been extremely swollen, were much smaller and I had gained $10 \mathrm{Kg}$.

Two months later when I paid another visit to the doctor, he did not even recognize me! $\mathrm{My} \mathrm{CD}_{4}$ count was now 450 cells $/ \mathrm{mm}^{3}$ and the viral load was 10,000 copies.

Around the fifth month of treatment, I suffered an attack of herpes zoster. I believe that the enormous amount of information I was reading on AIDS was affecting me negatively. I had just read a paper that described the most frequent opportunistic diseases of AIDS, particularly brain toxoplasmosis, and this information affected me greatly and caused a depressive effect on my immune system. Two days after I had read this paper, the first signs of herpes zoster appeared. It is impossible to forget that awful pain. It was as if I had stepped into Dante's Hell. On reflection today, it seems as if all the guilty feelings I had were manifesting themselves through wounds and pain.

During the first eight months, there was a change in the tuberculosis medication, together with a new drug called IDV, which is a protease inhibitor. This cocktail reduced the viremia to undetectable levels.

I became a loner, who only left home to go to work but never to have fun. I thought I had to be extremely careful, that I should avoid society, and I created a kind of shell by gaining a lot of weight until I actually became obese. I am 1.75 meters tall and I was weighing $100 \mathrm{Kg}$. Now I realize that this was a sign of depression. I told the first doctor that I was aware that I had become infected because I had sex without a condom, and that I felt guilty about this. I blamed myself for it, and these constant thoughts, over and over again, were very painful. He answered that at the time when I became infected with HIV, probably ten or twelve years previously, the scientific community knew very little about AIDS and the ways in which infection could occur.

I was suffering a lot emotionally so I decided to begin psychotherapy. I wanted to talk. I needed to share my fears, my thoughts. I wanted to overcome all that suffering. I needed to free myself from the shell I had built. I was referred to a psychiatrist and from the very beginning I felt her empathy towards my suffering.

The illness was under control but I wanted to get my life back. I had other issues to deal with as well as AIDS; issues I already had before I acquired the viral infection.

After 18 month, the doctor changed the medication, combining APV+AZT, and again the viral load remained below detectable levels. I would like to mention that during this decade of treatment I have never had to be hospitalized.

There was another change in the cocktail to $3 \mathrm{TC}+$ $\mathrm{d} 4 \mathrm{~T}+\mathrm{IDV}$, and once again the suppression of viral replication was achieved. Then there was yet another change; this time to AZT + NVP + APV, and the viral load marker remained the same. So, during that year and a half, I tried several new combinations of drugs to stop viral replication; whenever the viral load reached a detectable level, I was submitted to a change in the medication.

In 1999, the psychiatrist prescribed clonazepam because I was having a very hard time at work then and sleeping badly. I used this medication for five months and a viremia increase occurred, rising from undetectable levels to 70,000 copies. Apparently, the clonazepam was interfering with the $\mathrm{AZT}+\mathrm{EFZ}+\mathrm{d} 4 \mathrm{~T}$ $+\mathrm{APV}$, and I was forced to discontinue it.

Following determination of the virus genetic type, drug combination became easier and more efficient. 
Nevertheless, the following combinations failed to achieve the viral suppression that we had so hoped to obtain: NFV + 3TC + EFZ; RTV + NPV + AZT; $\mathrm{SQV}+\mathrm{APV}+\mathrm{d} 4 \mathrm{~T} ; \mathrm{RTV}+\mathrm{NFV}+\mathrm{AZT}$. Viral load varied between 1,000 and 100,000 copies.

This obliged the doctor to choose a drug combination different from the ones generally prescribed in the medical literature, and he decided to prescribe three different types of protease inhibitors: APV + RTV + IDV, which proved successful. However, I was told I would only be allowed to take this for six months. After this period, I was given DDI $+3 \mathrm{TC}+\mathrm{EFZ}+\mathrm{APV}$, which was effective but only for a certain period. I am now taking ATV + DDI + RTV + TFD. My CD 4 level is around 700 cells $/ \mathrm{mm}^{3}$ and my viral load under 5,000 copies.

It is now 2005. I feel healthy and I am optimistic about the future. I believe that this success is due to the building of the pillars I mentioned above: the love of my family and friends, a good patient/doctor relationship, as well as appropriate information on the illness and its treatment.

\section{Discussion}

Unlike many other paradigms in common use, a change model (like psychotherapy) recognizes both the potential chronicity of HIV/AIDS and the hope of recovery. When expectations of such an intervention are realistic, they offer an important basis for hope, and provide an incentive for patients and therapists to go on and improve their strategies for dealing with the patient who has HIV/AIDS [7,8].

Psychiatrists can play an important role in promoting patient adherence since comorbid psychiatric disorders, (e.g., substance abuse, depression or anxiety) have been shown to adversely affect patient compliance with an already complicated treatment regimen [9]. The psychiatric management of patients with HIV/AIDS includes:

- Establishing a therapeutic alliance.

o As the case report clearly shows, if the patient had stayed with the first doctor he was referred to, he would have died within a short period of time. His recovery was only possible thanks to his second doctor's decision to treat him, and the hope that the doctor was able to transmit to his patient.

- Diagnosing and treating all associated psychiatric disorders.

o The patient's depression interfered negatively with the treatment in several ways.

- Providing risk reduction strategies to further minimize the spread of HIV.

- Knowledge about the side effects of medication and drug interactions of psychotropic agents and HIV-related medications in order to provide optimum patient care.

o Information could result in improved medication management as well as the opportunity to monitor patient's clinical status and treatment response (behavioral skills) [10]. Nevertheless, one has to be careful how the information given is understood by the patient. Reading about HIV-related diseases had a very strong emotional effect on $\mathrm{G}$, which may indeed have interfered with his immunological system, contributing towards the outbreak of herpes zoster.

- Most of the psychotherapies included are flexible and dynamic.

- The therapist's qualities should include: empathy, good therapeutic relationship, optimistic reassurance and support to the patient, giving him hope [11].

The psychiatrist and the doctor in charge of treating the HIV-positive patient must work together and should communicate frequently. The psychiatrist should also be aware of the side effects of the medication and its related drug interactions with psychotropic agents. He/ she should also be knowledgeable about HIV-related medications in order to provide optimum patient care $[12,13]$.

o When $\mathrm{G}$ was prescribed clonazepam, he was depressed, anxious and suffered from 
insomnia. His viral load had increased to 70,000 copies before the specialist discovered the interactions of clonazepam and its side effects. The psychiatrist was unaware of this at the time.

- Current level of support from family and society. o G stresses the importance of his family's support to his very survival. We know that patients abandoned by their families who have no other social support tend to have a much worse prognosis, and their adherence to treatment is poorer. They also tend to have more psychiatric comorbidities.

- Psychiatric symptoms and problems must be perceived and treated fast.

The objectives of therapy must include the degree to which the therapist can encourage discussion of the patient's treatment goals, the patient's commitment to adherence to medication, and strategies implemented to increase the patient's motivation to change his lifestyle and to assure his adherence to treatment.

On the other hand, the patient values the psychotherapist's work, and during this treatment attention should be paid to the patient's ego defenses and the defenses that appear during therapy of painful affective states. This can be used, for example, to treat the stress that is a result of the use of prescribed medication.

\section{Clinical Follow-up and Prognosis}

Overall, a hopeful outlook seems justified. A longterm treatment goal will be to empower $\mathrm{G}$ to deal with the stressors in his life and to prevent depression. The overall prognosis for $\mathrm{G}$ is favorable. He has a supportive, loving family, does well professionally and has a positive affect.

\section{Conclusions}

In conclusion, the following topics should be emphasized:
1. Family support: Many studies have been carried out on this subject. Patients who have greater family support comply better with treatment.

2 . Comorbidity: Patients with depression or anxiety have a poorer compliance with treatment.

3. A good response to ARV treatment is a condition that encourages patients to seek medical care and to adhere to the treatment.

4. Therapeutic relationship. In this case, it may have been responsible for the success of the treatment. $G$ at first had two specialists who did not know how to work with his case.

5. The importance of associated treatment (psychotherapy plus psychiatry plus clinical care) may be the greatest success factor, the biopsychosocial association providing better adherence and a better quality of life for this patient.

6. Psychiatric care and support help establish a high level of motivation towards treatment, health in general and a better quality of life.

As this report clearly shows, it was the combination of many factors that led to this patient's successful treatment. In HIV treatment, it is clear that good medical practice, fortunately, is still the most important factor in combining technical proficiency with the art of human warmth and compassion.

\section{References}

1. Martin P., Ferreri M. Depression et le concept de qualité de vie. Paris. France. Ardix Medical 1997;48.

2. Ickovics J.R., Meisler A.W. Adherence in AIDS clinical trials: a framework for clinical research and clinical care. J Clin Epidemiol 1997;50(4):385-91.

3. Molaghan J.B. Adherence issues in HIV therapeutics introduction: the situation. J Assoc Nurses AIDS Care 1997;8 (Suppl):7-9. 
4. Garcia R., Schooley R.T., Badaró R. Na adherence trilogy is essential for long-term HAART success. The Brazilian Journal of Infectious Diseases 2003;7(5):307-14.

5. Pincus H.A., Zarin D.A., Tanielian T.L., et al. Psychiatric patients and treatments in 1997: findings from the American Psychiatric Association Practice Research Network. Arch Gen Psychiatry 1999;56:441-9.

6. Farber E.W., Mirsalimi H., Williams K.A., McDaniel J.S. Meaning of illness and psychological adjustement to HIV/AIDS. Psychosomatics 2003;44(6):485-91.

7. Engel G..L. The biopsychosocial model and medical education: who are to be the teachers? N Engl J Med 1982;306:802-5.

8. Gabbar G.O., Kay J. The Fate of Integrated Treatment: Whatever Happened to the Biopsychosocial Psychiatrist? Am J Psychiatry 2001;158:1956-63.

9. Figueiredo R.M., Sinkoc V.M., Gallani M.B.J., et al. Adherence of patients with AIDS to treatment with antiretroviral medications: difficulties related and proposition of attenuating measures. Proceedings of the $12^{\text {th }}$ World AIDS Conference; 1998 June-July; Geneva: Conference Record 1998:862.

10. Facilitating adherence to the overall treatment plan Practice guideline for the treatment of patients with HIV/ AIDS. Am J Psychiatry 2000 Nov;157(11 Suppl):1-62. [473 references] Guideline Committee Work Group on HIV/AIDS. Group Members: J. Stephen McDaniel, Joyce Y. Chung, Larry Brown, et al.

11. Del Giglio A. A relação médico paciente sob uma perspectiva dialógica. Revista Brasileira de clínica e terapêutica 2002,27:1:6-8.

12. Kessler D.A. Communicating with patients about their medications. The New England Journal of Medicine. 1991;5:1650-2.

13. Fallowfield L., Jenkins V. Communicating sad, bad and difficult news in medicine. Lancet 2004;(9405):312-9. 